\title{
Circulating Adrenomedullin Is Increased in Preterm Newborns Developing Intraventricular Hemorrhage
}

\author{
DIEGO GAZZOLO, EMANUELA MARINONI, LIA GIOVANNINI, CLAUDIO LETIZIA, \\ GIOVANNI SERRA, AND ROMOLO DI IORIO \\ Department of Neonatology, "G. Gaslini" University Hospital, Genoa, Italy [D.G., L.G., G.S.]; \\ Laboratory of Perinatal Medicine and Molecular Biology, Second Institute of Obstetrics and Gynecology \\ [E.M., R.D.], and Department of Internal Medicine [C.L.], University "La Sapienza," Rome, Italy
}

\begin{abstract}
Adrenomedullin is a novel vasoactive peptide that participates in cerebral blood flow regulation and circulates in human plasma. To verify whether plasma adrenomedullin is able to identify preterm newborns at risk of intraventricular hemorrhage (IVH), we performed a case-control study. Plasma samples collected within $6 \mathrm{~h}$ after birth in 24 preterm newborns who developed IVH, as diagnosed at $72 \mathrm{~h}$, were assessed for adrenomedullin and compared with those obtained from 48 preterm newborns, matched for gestational age, who did not develop IVH. Cerebral ultrasound and Doppler velocimetry waveform patterns in the middle cerebral artery were also recorded at the time of blood sampling. Adrenomedullin blood concentrations and middle cerebral artery pulsatility index values were significantly higher in infants developing IVH $(20.1 \pm 4.5 \mathrm{fmol} / \mathrm{mL}$ and $1.71 \pm 0.21 \mathrm{fmol} / \mathrm{mL}$, respectively) than in controls $(7.5 \pm$ $3.0 \mathrm{fmol} / \mathrm{mL}$ and $1.49 \pm 0.19 \mathrm{fmol} / \mathrm{mL}$, respectively). Adrenomedullin blood concentrations correlated with middle cere-
\end{abstract}

bral artery pulsatility index $(r=-0.77, p<0.01)$ and with the grade of IVH extension $(r=0.83, p<0.01)$. This study suggests that adrenomedullin blood concentration might be a promising tool for identifying preterm infants at risk of IVH immediately after birth, when imaging assessment and clinical symptoms of hemorrhage are still silent. (Pediatr Res 50: 544-547, 2001)
Abbreviations:
IVH, intraventricular hemorrhage
CGRP, calcitonin gene-related peptide
FHR, fetal heart rate
MCA PI, middle cerebral artery pulsatility index
NICU, neonatal intensive care unit
RDS, respiratory distress syndrome
$\mathbf{P v o}_{2}$, venous oxygen partial pressure
$\mathrm{PvCO}_{2}$, venous carbon dioxide partial pressure

IVH is the most common variety of cerebral hemorrhage, affecting about 15 to $20 \%$ of preterm infants, which continues to represent one of the major problems in the NICU (1). Perinatal asphyxia constitutes a risk in preterm infants by altering cerebral blood flow regulatory mechanisms (e.g.; hemodynamic, neurogenic, and metabolic mechanisms) and causing loss of cerebral vascular autoregulation. Hypotension, cerebral ischemia, and reperfusion are the main events involved in vascular autoregulation (2-4). Severe and prolonged hypoxia or ischemia result in cell death and tissue damage. Reperfusion could be critical because organ damage, particularly of the brain, may be amplified during this period. An exaggerated release of vasoactive agents, acting in autocrineparacrine manner, could be responsible for reperfusion injury (5), which, in turn, leads to IVH.

Received July 3, 2000; accepted March 23, 2001

Correspondence: Diego Gazzolo, M.D., Dept of Neonatology, “G. Gaslini” University Hospital, Via Oberdan 80/1, 16167 Genoa, Italy; e-mail: dgazzolo@hotmail.com Supported, in part, by the Italian National Research Council (CNR).
Adrenomedullin is a 52-amino acid, newly discovered vasoactive peptide first isolated from pheochromocytoma, that shares some homology with CGRP (6). Cultured vascular endothelial cells and smooth muscle cells produce adrenomedullin (7), which elicits its vasodilator activity through an increase in intracellular cAMP (8). Adrenomedullin has been identified in a variety of tissues, including the CNS, and adrenomedullin-like immunoreactivity has been also described in human cerebrospinal fluid (9). More recently, it has been reported that adrenomedullin also exerts vasodilator activity in the cerebral circulation $(10,11)$ and that this peptide is involved in the regulation of systemic and local blood flow during neonatal cardiovascular adaptation $(12,13)$ and during birth stress (14). In human fetuses, there is evidence that adrenomedullin participates in cerebral fetal hemodynamic modifications (15).

We hypothesized that adrenomedullin plasma levels would increase as a response to ischemic insult and overshoot cerebral blood flow during the reperfusion period. Therefore, the 
present study was aimed to investigate whether plasma adrenomedullin concentrations sampled a few hours after birth may be used to identify preterm newborns with high risk of IVH.

\section{MATERIALS AND METHODS}

Population. We performed a case-control study on 24 preterm newborns (27-35 wk of gestation) with IVH. Diagnosis of IVH was performed at $72 \mathrm{~h}$ from birth by ultrasound scanning (16); 8 infants were diagnosed to have a grade I IVH, 11 grade II, and 5 grade III. At admission to the NICU, all newborns are routinely sampled for the assessment of clinical parameters (red blood cell count, venous blood $\mathrm{pH}$, ion concentrations, plasma glucose level, arterial blood pressure) and undergo cerebral ultrasound and Doppler examination. After IVH was diagnosed, clinical and laboratory parameters and Doppler velocimetry values, recorded within $6 \mathrm{~h}$ after birth, were re-evaluated and compared with those obtained from 48 preterm infants, matched for gestational age, who were admitted consecutively to each IVH case to the NICU and who did not develop IVH (two control infants for each IVH infant). Exclusion criteria were multiple pregnancies, maternal hypertension, diabetes and infections, clinical evidence of chorioamnionitis, premature rupture of membranes ( $>24 \mathrm{~h}$ ), fetal malformations, and chromosomal abnormalities.

Clinical characteristics at birth are shown in Table 1. Emergency cesarean section was performed in 11 out of 24 cases in the IVH group and in 24 of 48 cases in the control group; indications included placental abruptio and nonreassuring fetal status as defined by the American College of Obstetricians and Gynecologists (bradycardia, fetal heart rate late decelerations, severe and repetitive fetal heart rate variable decelerations, reduced beat-to-beat variability) (17). Corticosteroid therapy was administrated (betamethasone $12 \mathrm{mg} / 24 \mathrm{~h}$ for $2 \mathrm{~d}$ i.m., Bentelan, GlaxoWellcome, Verona, Italy) in 14 out of 24 cases in the IVH group and in 29 of 48 cases in the control group. Fourteen out of 32 women who delivered vaginally received tocolytic therapy (ritodrine $30-50 \mathrm{mg} / \mathrm{h}$ i.v., Miolene, Lusofarmaco, Milan, Italy). In 28 infants (10 in the IVH group and 18 among the controls) the birth weight was $<10$ th percentile for gestational age. None of the newborns were delivered by forceps.

The study protocol was approved by the Ethics Committee of the "Giannina Gaslini" Children's Hospital, University of Genoa, and the parents of the subjects examined gave informed consent.

Table 1. Clinical characteristics of study groups at birth

\begin{tabular}{lcc}
\hline & $\begin{array}{c}\text { IVH } \\
(n=24)\end{array}$ & $\begin{array}{c}\text { Controls } \\
(n=48)\end{array}$ \\
\hline Gestational age at birth $(\mathrm{wk})$ & $32.7 \pm 2.0$ & $32.5 \pm 2.4$ \\
Birth wt $(\mathrm{g})$ & $1641 \pm 395$ & $1671 \pm 356$ \\
Birth wt $<$ 10th percentile $(n)$ & $10(41 \%)$ & $18(37 \%)$ \\
Cesarean section $(n)$ & $11(46 \%)$ & $24(50 \%)$ \\
Apgar score, 1 min & $7.0 \pm 1.6$ & $6.6 \pm 2.0$ \\
Apgar score, 5 min & $8.2 \pm 0.6$ & $8.3 \pm 0.7$ \\
\hline
\end{tabular}

Values are expressed as mean \pm SD. There were no statistical differences between the two groups.
Cerebral ultrasound and Doppler velocimetry. Standard cerebral ultrasound was performed by a real-time ultrasound machine and a pulsed Doppler apparatus (Acuson 128SP5, Acuson, Mountain View, CA, U.S.A.) was used for blood flow velocity measurements of the pulsatility index (PI) in the middle cerebral artery (MCA), performed at the same time of blood sampling.

Adrenomedullin measurement. Plasma adrenomedullin concentration was measured after extraction and purification, as reported (18), in $500 \mu \mathrm{L}$ of samples collected at admission to the NICU for clinical evaluation, and stored at $-20^{\circ} \mathrm{C}$. A specific RIA kit (Phoenix Pharmaceuticals, Mountain View CA, U.S.A.) with rabbit polyclonal antibody raised against human adrenomedullin 1-52 was used. Each measurement was performed in duplicate and the averages were reported. The sensitivity of the assay was $0.34 \mathrm{fmol} / \mathrm{mL}$. The antibody cross-reacts $100 \%$ with human adrenomedullin and no crossreactivity was reported with rat adrenomedullin, amylin, CGRP, endothelin-1, $\alpha$-atrial natriuretic peptide, or brain natriuretic peptide. The intra- and interassay coefficients of variance were $5.1 \%$ and $12.0 \%$, respectively.

Statistical analysis. Data are expressed as mean \pm SD. Adrenomedullin blood concentrations and neonatal monitoring parameters between the groups were analyzed by means of Mann-Whitney U two-sided test. Comparison between proportions was performed with Fisher's exact test; correlation between adrenomedullin levels and MCA PI was analyzed by linear regression analysis. Multiple linear regression analysis was performed with adrenomedullin as the dependent variable to analyze the influence of various clinical parameters (occurrence of IVH, MCA PI, mode of delivery, indication for cesarean section, gestational age, birth weight, Apgar score, incidence of respiratory distress syndrome [RDS], corticosteroids and tocolytic therapy) on adrenomedullin values. A value of $p<0.05$ was considered as significant.

\section{RESULTS}

At blood sampling performed within $6 \mathrm{~h}$ after birth, no significant differences were observed in laboratory parameters between the two study groups (Table 2). Although no cerebral ultrasound features suggestive of IVH were observed during the first $48 \mathrm{~h}$ of age, MCA PI recorded at the time of blood sampling was significantly higher $(p<0.01)$ in infants developing IVH. In this group, mean adrenomedullin concentration was significantly higher $(p<0.01)$ than in controls, being 20.1 $\pm 4.5 \mathrm{fmol} / \mathrm{mL}$ and $7.5 \pm 3.0 \mathrm{fmol} / \mathrm{mL}$, respectively (Fig. 1). As shown in Figure 2, there was a negative correlation $(r=$ $-0.75 ; p<0.01)$ between adrenomedullin concentrations and MCA PI values in IVH group, whereas no correlation was found in the control group $(r=0.20)$. In IVH group, higher adrenomedullin concentrations were found in infants who developed a more severe IVH (grades II and III) when compared with IVH grade I $(23.2 \pm 2.3 \mathrm{fmol} / \mathrm{mL}$ versus $14.9 \pm 0.9$ $\mathrm{fmol} / \mathrm{mL} ; p<0.05)$. There was a significant correlation between adrenomedullin levels and degree of brain lesion $(r=$ $0.83 ; p<0.01)$, whereas no correlation was present between MCA PI assessed within $6 \mathrm{~h}$ after birth and severity of IVH $(r$ 
Table 2. Neonatal monitoring parameters at blood sampling performed within $6 \mathrm{hr}$ from birth in infants developing IVH and controls

\begin{tabular}{|c|c|c|}
\hline & $\begin{array}{c}\text { IVH } \\
(n=24)\end{array}$ & $\begin{array}{l}\text { Controls } \\
(n=48)\end{array}$ \\
\hline $\operatorname{RBC}\left(10^{6} / \mathrm{L}\right)$ & $4.2 \pm 0.2$ & $4.2 \pm 0.3$ \\
\hline $\mathrm{Hb}(\mathrm{g} / \mathrm{L})$ & $13.7 \pm 3$ & $13.9 \pm 2$ \\
\hline Ht $(\%)$ & $41.4 \pm 2.4$ & $41.7 \pm 3.2$ \\
\hline $\mathrm{pH}$ & $7.30 \pm 0.4$ & $7.32 \pm 0.1$ \\
\hline $\mathrm{PvCO}_{2}(\mathrm{kPa})$ & $5.84 \pm 1.5$ & $5.83 \pm 1.2$ \\
\hline $\mathrm{PvO}_{2}(\mathrm{kPa})$ & $4.16 \pm 0.9$ & $4.19 \pm 1.1$ \\
\hline $\mathrm{BE}(\mathrm{mmol} / \mathrm{L})$ & $-2.1 \pm 1.9$ & $-1.7 \pm 2$ \\
\hline $\mathrm{Na}^{+}(\mathrm{mmol} / \mathrm{L})$ & $138 \pm 5$ & $140 \pm 3$ \\
\hline $\mathrm{K}^{+}(\mathrm{mmol} / \mathrm{L})$ & $4.1 \pm 0.3$ & $4.1 \pm 0.2$ \\
\hline $\mathrm{Ca}^{++}(\mathrm{mmol} / \mathrm{L})$ & $1.14 \pm 0.08$ & $1.15 \pm 0.1$ \\
\hline Plasma glucose $(\mathrm{mmol} / \mathrm{L})$ & $4.1 \pm 1.1$ & $4.3 \pm 1.1$ \\
\hline Systolic arterial pressure $(\mathrm{kPa})$ & $44.2 \pm 13.1$ & $45.3 \pm 12.3$ \\
\hline Diastolic arterial pressure $(\mathrm{kPa})$ & $24.7 \pm 11.1$ & $25.3 \pm 10.2$ \\
\hline MCA PI & $1.71 \pm 0.21 *$ & $1.49 \pm 0.19$ \\
\hline
\end{tabular}

Values are expressed as mean $\pm \mathrm{SD}$. RBC, red blood cells; BE, base excess; $\mathrm{PvO}_{2}$, venous oxygen partial pressure; $\mathrm{PvCO}_{2}$, venous carbon dioxide partial pressure.

$* p<0.01$.

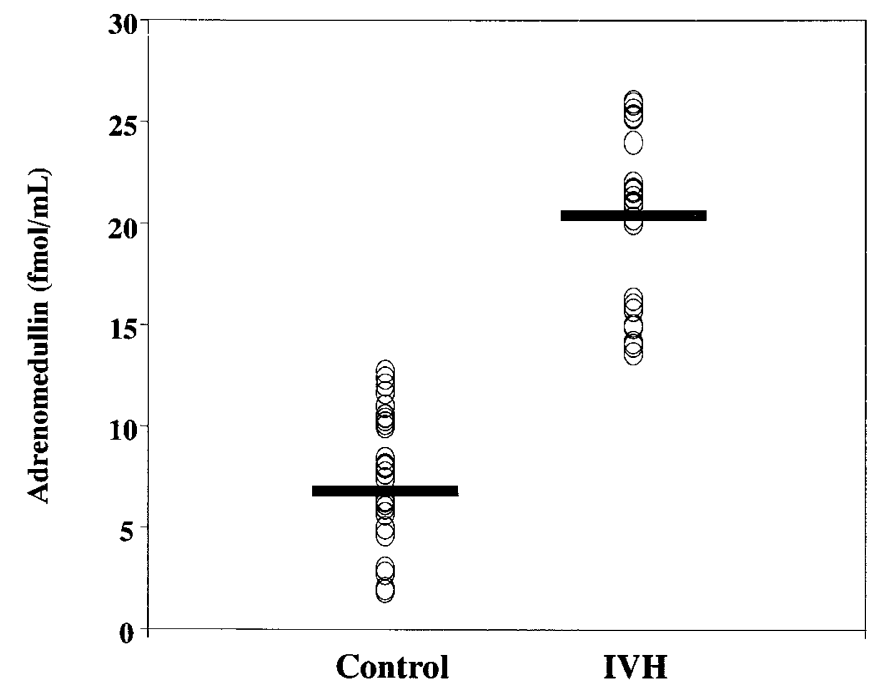

Figure 1. Individual values of adrenomedullin concentrations in plasma of newborns who did not develop IVH (controls) and in those that developed IVH (IVH). Horizontal bars represent the mean values. Values for IVH were higher than those for controls $(p<0.01$, Mann-Whitney U two-sided test).

$=0.29 ; p>0.05)$. The incidence of RDS was not significantly different in the two groups (IVH group: $n=12$; controls: $n=$ 10) and was not significantly associated with adrenomedullin levels (odds ratio $=0.38$ ). All the other clinical and laboratory parameters were not correlated with adrenomedullin concentrations and multiple linear regression analysis confirmed a significant correlation between adrenomedullin and MCA PI ( $p$ $<0.001$ ) and showed that the occurrence of IVH represented an independent variable associated with adrenomedullin values $(p<0.001)$ (Table 3).

\section{DISCUSSION}

The present study shows that, within a few hours after birth, circulating adrenomedullin was increased in infants who later

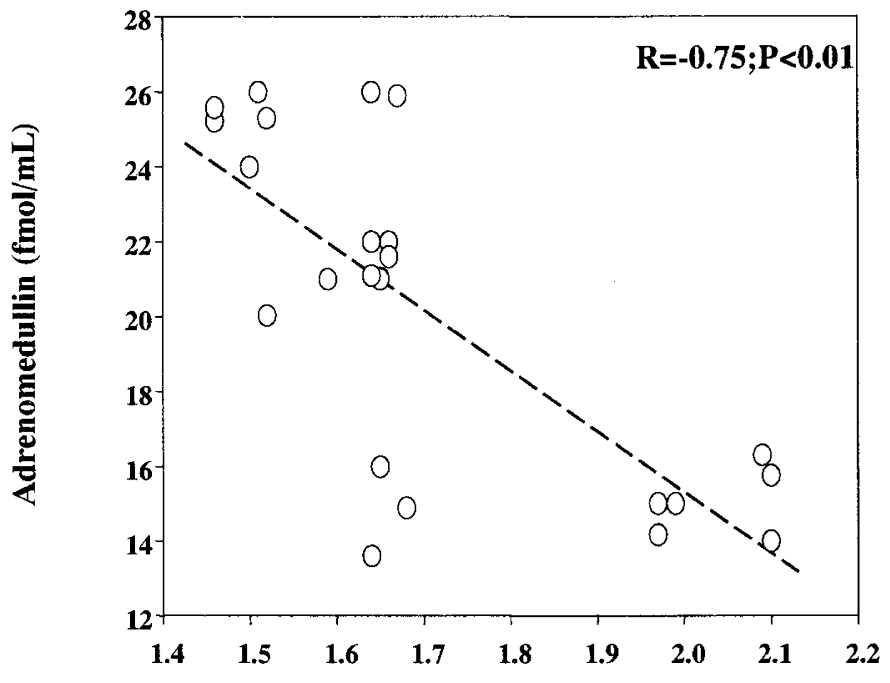

\section{MCA PI}

Figure 2. Correlation between plasma adrenomedullin concentrations and MCA PI in the 24 infants developing IVH. Regression line is shown.

Table 3. Relationship of various independent variables with adrenomedullin levels analyzed by multiple linear regression

\begin{tabular}{lccc}
\hline \multicolumn{1}{c}{ Variable } & $\begin{array}{c}\text { Regression } \\
\text { coefficient }\end{array}$ & $\begin{array}{c}\text { Standard } \\
\text { Error }\end{array}$ & $p$ \\
\hline Constant & 11.180 & 11.10 & 0.318 \\
Gestational age & -0.079 & 0.210 & 0.701 \\
Birth wt & 0.003 & 0.001 & 0.200 \\
Cesarean section & -0.566 & 0.846 & 0.513 \\
Apgar score, 1 min & -0.089 & 0.249 & 0.722 \\
Apgar score, 5 min & 1.029 & 0.759 & 0.180 \\
Corticosteroid therapy & -1.226 & 0.894 & 0.176 \\
Respiratory distress syndrome & -0.357 & 0.938 & 0.705 \\
Tocolytic therapy & -1.590 & 1.067 & 0.141 \\
MCA PI & -7.889 & 2.152 & $<0.001$ \\
IVH & 13.73 & 0.966 & $<0.001$ \\
\hline
\end{tabular}

developed IVH, suggesting that adrenomedullin might play a role in the modifications of cerebral circulation.

Human and experimental studies on cerebral blood flow have demonstrated the importance of the cerebrovascular autoregulation, which is under control of metabolic, myogenic, and neurologic mechanisms. The main events causing loss of vascular autoregulation, which can lead to IVH, are commonly identified in hypotension, cerebral ischemia, and reperfusion hyperemia (3-5). In vitro and in vivo studies have shown that adrenomedullin is secreted by endothelial cells (7) and participates in the regulation of cerebral blood flow $(10,11)$; adrenomedullin infusion in dogs increases cerebral blood flow in a dose-dependent manner without affecting systemic blood pressure and other cardiovascular parameters (19). Recently, we have shown that adrenomedullin contributes to the hemodynamic modifications that determine the occurrence of the brain-sparing effect in growth retarded fetuses, confirming an important role of this peptide in the regulation of fetal cerebral blood flow in humans (15). In the present study, higher levels of adrenomedullin were found in infants with increased resis- 
tance to cerebral blood flow as detected by Doppler ultrasound. Increased plasma levels of adrenomedullin could be the result of an enhanced release of the peptide by vascular endothelial cells in an attempt to compensate reduced blood flow. Because it has been shown that reperfusion injury resulting from reactive excessive vasodilatation is a primary event in the occurrence of IVH, adrenomedullin released in response to vasoconstriction might have a role in the loss of cerebral vascular autoregulation that leads to brain injury. In this light, it has been demonstrated that adrenomedullin exacerbates ischemic brain damage in rats $(20)$.

On the other hand, it is also possible that the same pathologic events leading to IVH are also responsible for stimulation of adrenomedullin release. Cerebral blood flow autoregulation in preterm infants is very sensitive to perinatal hypoxicischemic insult (5), which represents the major cause of IVH. It has been demonstrated that hypoxia stimulates adrenomedullin mRNA expression and peptide production in different type of cells $(21,22)$ and circulating adrenomedullin is increased in human subjects maintained in hypoxic condition (23). Moreover, in preterm infants it has been demonstrated that ischemia and reperfusion induce an inflammatory response with enhanced cytokines expression (5), which are known to stimulate adrenomedullin release (24). Thus, elevated adrenomedullin concentrations found in infants developing IVH may derive from direct stimulation of peptide release from endothelial or neuronal cells induced by hypoxia or inflammatory mediators. Last, we cannot exclude that other factors may independently affect adrenomedullin levels and occurrence of IVH, however, multivariate analysis failed to show any significant correlation between adrenomedullin and other clinical variables, such as mode of delivery, gestational age, birth weight, indication for cesarean section, incidence of RDS, or maternal therapy.

In conclusion, adrenomedullin plasma levels in preterm infants soon after birth might be a promising tool for the early detection of infants at risk for IVH. The mechanism that gives rise to this increase and its relevance to the pathophysiology of IVH remain to be established.

\section{REFERENCES}

1. Philip AG, Allan WC, Tito AM, Wheeler LR 1989 Intraventricular hemorrhage in preterm infants: declining incidence in the 1980s. Pediatrics 84:797-801
2. Volpe JJ 1995 Intracranial hemorrhage: germinal matrix-intraventricular hemorrhage of the premature infant. In: Volpe JJ (ed) Neurology of the Newborn. Saunders, Philadelphia, pp 403-463

3. Paulson OB, Strangaard S, Edvinsson L 1990 Cerebral autoregulation. Cerebrovasc Brain Metab Rev 2:161-192

4. Vannucci RC 1993 Mechanisms of perinatal hypoxic ischemic brain damage. Semin Perinatol 17:330-337

5. Fellman V, Raivio KO 1997 Reperfusion injury as the mechanism of brain damage after perinatal asphyxia. Pediatr Res 41:599-606

6. Kitamura K, Kangawa K, Kawamoto M, Ichiki Y, Nakamura S, Matsuo H, Eto T 1993 Adrenomedullin: a novel hypotensive peptide isolated from human pheochromocytoma. Biochem Biophys Res Commun 192:553-560

7. Sugo S, Minamino N, Kangawa K, Miyamoto K, Kitamura K, Sakata J, Eto T, Matsuo H 1994 Endothelial cells actively synthesize and secrete adrenomedullin. Biochem Biophys Res Commun 201:1160-1166

8. Ishizaka Y, Ishizaka Y, Tanaka M Kitamura K, Kangawa K, Minamino N, Matsuo H, Eto T 1994 Adrenomedullin stimulates cyclic AMP formation in rat vascular smooth muscle cells. Biochem Biophys Res Commun 200:642-646

9. Takahashi K, Sone M, Satoh F, Murakami O, Totsune K, Tanji H, Sato N, Ito H, Mouri T 1997 Presence of adrenomedullin-like immunoreactivity in the human cerebrospinal fluid. Peptides 18:459-461

10. Dogan A, Suzuki Y, Koketsu K 1997 Intravenous infusion of adrenomedullin and increase in regional cerebral blood flow and prevention of ischemic brain injury after middle cerebral artery occlusion in rats. J Cereb Blood Flow Metab 17:19-25

11. Lang MG, Paterno R, Faraci FM, Heistad DD 1997 Mechanisms of adrenomedullininduced dilatation of cerebral arterioles. Stroke 28:181-185

12. Marinoni E, Di Iorio R, Alò P, Villaccio B, Alberini A, Cosmi EV 1999 Immunohistochemical localization of adrenomedullin in fetal and neonatal lung. Pediatr Res 45:282-285

13. Rudolph AM 1998 Adrenomedullin: its role in perinatal adaptation. Acta Paediatr $87: 236$

14. Bold T, Luukkainen P, Fyhrquist F, Pohjavuori M, Andersson S 1998 Birth stress increases adrenomedullin in the newborn. Acta Paediatr 87:93-94

15. Di Iorio R, Marinoni E, Letizia C, Gazzolo D, Lucchini C, Cosmi EV 2000 Adrenomedullin is increased in the feto-placental circulation in intrauterine growth retardation with abnormal umbilical artery waveforms. Am J Obstet Gynecol 18:650654

16. Papile LA, Burnstein J, Burnstein R, Koffler H 1978 Incidence and evolution of subependymal and intraventricular hemorrhage: a study of infants with birth weight less than $1.500 \mathrm{gm}$. J Pediatr 92:529-534

17. ACOG Committee Opinion 1998 Inappropriate use of the terms fetal distress and birth asphyxia. Int J Gynecol Obstet 61:309-310

18. Di Iorio R, Marinoni E, Letizia C, Alò P, Villaccio B, Cosmi EV 1998 Adrenomedullin, a new vasoactive peptide, is increased in preeclampsia. Hypertension 32:758-763

19. Baskaya MK, Suzuki Y, Anzai M, Seki Y, Saito K, Takayasu M, Shibuya M, Sugita K 1995 Effects of adrenomedullin, calcitonin gene-related peptide, and amylin on cerebral circulation in dogs. J Cereb Blood Flow Metab 15:827-834

20. Wang X, Yue T, Barone FC, White RF, Clark RK, Willette RN, Sulpizio AC, Aiyar NV, Ruffolo RR, Feuerstein GZ 1995 Discovery of adrenomedullin in rat ischemic cortex and evidence for its role in exacerbating focal brain ischemic damage. Proc Natl Acad Sci U S A 92:11480-11484

21. Cormier-Regard S, Nguyen SV, Claycomb WC 1998 Adrenomedullin gene expression is developmentally regulated and induced by hypoxia in rat ventricular cardiac myocytes. J Biol Chem 273:1787-1792

22. Nakayama M, Takahashi K, Murakami O, Shirato K, Shibahara S 1998 Induction of adrenomedullin by hypoxia and cobalt chloride in human colorectal carcinoma cells. Biochem Biophys Res Commun 243:514-517

23. Toepfer M, Hartmann G, Schlosshauer M, Hautmann H, Tschop M, Fischer R, Huber RM 1998 Adrenomedullin: a player at high altitude? Chest 113:1428

24. Sugo S, Minamino N, Shoji H, Kangawa K, Kitamura K, Eto T, and Matsuo H 1995 Interleukin-1, TNF and lipopolysaccharide additively stimulate production of adrenomedullin in vascular smooth muscle cells. Biochem Biophys Res Commun 207:25-32 